\title{
A NEW SPECIES OF THE GENUS PILOBATES (ACARI, ORIBATIDA, HAPLOZETIDAE) FROM MADAGASCAR
}

\author{
Sergey G. Ermilov ${ }^{1^{*}}$ and Josef Starý ${ }^{2}$
}

\author{
${ }^{1} \mathrm{X}$-BIO Institute, Tyumen State University, Tyumen, Russia \\ ${ }^{2}$ Biology Centre v.v.i., Czech Academy of Sciences, Institute of Soil Biology, České Budějovice, \\ Czech Republic \\ *corresponding author; e-mail: ermilovacari@yandex.ru
}

\begin{abstract}
A new oribatid mite species of the genus Pilobates (Oribatida, Haplozetidae) is described from Madagascar, based on material collected from litter in Andasibe-Mantadia National Park, eastern Madagascar. Pilobates longiprocessus sp. n. differs from Pilobates africanus Ermilov and Starý, 2020 in the presence of simple notogastral setae and leg trochanters IV with triangular process distodorsally. An identification key to known species of Pilobates is provided.
\end{abstract}

KEY WORDS: Oribatid mites, systematics, morphology, identification key, Madagascar.

DOI: 10.21684/0132-8077-2020-28-2-123-128

\section{INTRODUCTION}

This work, based on oribatid mite material collected from Andasibe-Mantadia National Park in 2010, is part of our continuing study of oribatid mites (Acari, Oribatida) of Madagascar (e.g., Ermilov and Starý 2020a-c).

During the taxonomic identification of representatives of the family Haplozetidae, we found one new species, belonging to Pilobates Balogh, 1960. This genus comprises six species which are distributed in the Ethiopian region (mostly Madagascar) and in the Mediterranean. The revised generic diagnosis has been presented by Ermilov (2020). The primary identification key to four species of Pilobates has been provided earlier by Ermilov and Starý (2020c).

The primary goal of our paper is to describe and illustrate this new species. In addition, an updated identification key to the species of Pilobates is provided.

\section{MATERIALS AND METHODS}

Specimens. Mites were extracted from samples into $75 \%$ ethanol using Winkler apparatus in laboratory conditions.

Subsequent to the study, the specimens have been distributed among two institutions: the Senckenberg Museum, Görlitz, Germany (SM) and the Tyumen State University Museum of Zoology, Tyumen, Russia (TSUMZ).

Observation and documentation. Specimens were mounted in lactic acid on temporary cavity slides for measurement and illustration. Body length was measured in lateral view, from the tip of the rostrum to the posterior edge of the notogaster. Notogastral width refers to the maximum width of the notogaster in dorsal view (behind pteromorphs).
Lengths of body setae were measured in lateral aspect. All body measurements are presented in micrometers $(\mu \mathrm{m})$. Formulas for leg setation are provided in parentheses according to the sequence trochanter-femur-genu-tibia-tarsus (famulus included). Formulas for leg solenidia are provided in square brackets, according to the sequence genu-tibia-tarsus.

Drawings were made with a camera lucida using a Leica transmission light microscope "Leica DM 2500".

Terminology. Morphological terminology used in this paper follows that of F. Grandjean: see Travé and Vachon (1975) for references, Norton (1977) for leg setal nomenclature, and Norton and BehanPelletier (2009) for overview.

Abbreviations. Prodorsum: lam-lamella; slam-sublamella; $\mathrm{Al}$ - sublamellar porose area; $t u$-tutorium; ro, le, in, $b s$-rostral, lamellar, interlamellar and bothridial setae, respectively; $A d$ - sejugal porose area; $D$ - dorsophragma; $P$ pleurophragma. Notogaster: $c, d a, d m, d p, l a, l m$, $l p, h, p$-notogastral setae; $S a, S 1, S 2, S 3$-notogastral sacculi; ia, im, ip, ih, ips-notogastral lyrifissures; gla-opisthonotal gland opening. Gnathosoma: $a, m, h$-subcapitular setae. Epimeral and lateral podosomal regions: $1 a, 1 b, 1 c, 2 a$, $3 a, 3 b, 3 c, 4 a, 4 b, 4 c$ - epimeral setae; PdI, PdIIpedotecta I, II, respectively; dis - discidium; $c p$ circumpedal carina. Anogenital region: $g$, ag, an, ad-genital, aggenital, anal and adanal setae, respectively; iad - adanal lyrifissure; Amar - marginal porose area; $p o$ - preanal organ. Legs: $\mathrm{Tr}, \mathrm{Fe}$, $\mathrm{Ge}, \mathrm{Ti}, \mathrm{Ta}-\mathrm{leg}$ trochanter, femur, genu, tibia, tarsus, respectively; $p a-$ leg porose area; $\omega, \sigma$, $\varphi$-leg solenidia; $\varepsilon$ - leg famulus; $d, l, v, b v, e v, f t$, tc, it, $p, u, a, s, p v, p l$-leg setae. 
SYSTEMATICS

Superfamily Oripodoidea

Family Haplozetidae

Genus Pilobates Balogh, 1960

Type species Protoribates pilosellus Balogh, 1958

\section{Pilobates longiprocessus Ermilov and Starý, sp.n.}

Figs. 1-7

Diagnosis. Body size: 747-929 × 464-581. Rostral, lamellar and interlamellar setae long, setiform, barbed, in longest, ro shortest. Bothridial seta long, thickened, ciliate. Tutorium of medium length. All notogastral setae short, setiform, thin, roughened. All notogastral sacculi elongate. Three pairs of aggenital setae. Adanal setae $a d_{1}, a d_{2}$ long, thickened, erect, barbed. Legs monodactylous. Leg trochanter IV with long triangular process distodorsally.

Description. Measurements. Body length: 879 (holotype, female), 747-929 (four paratypes, two males and two females); notogaster width: 547 (holotype), 464-581 (four paratypes). Females larger than males: $813-929 \times 498-581$ vs. $747-$ $796 \times 464-481$.

Integument (Fig. 5). Body color light brown to brown. Body and leg surface microporose (distinctly visible under magnification above 400). Ventroantiaxial side of leg femur II densely striate. Paraxial side of all femora with seldom stria.

Prodorsum (Figs. 1, 3). Rostrum broadly rounded. Lamella about $1 / 2$ length of prodorsum. Sublamella short, $1 / 3$ or $1 / 4$ length of lamella. Sublamellar porose area (20-28) rounded, located ventral to sublamella. Tutorium of medium length, shorter than lamella, ridge-like. Rostral (82-94), lamellar (143-155) and interlamellar (176-188) setae setiform, barbed, le inserted on lamellar end. Bothridial seta (151-164) thickened (without developed head), bilaterally shortly ciliate. Exobothridial seta and its alveolus not observed. Sejugal porose area poorly visible, narrowly elongate oval, located posteriorly to interlamellar seta.

Notogaster (Figs. 1, 3). Anterior notogastral margin slightly convex medially. Pteromorph triangular, rounded laterally, with distinct hinge. Fourteen pairs of notogastral setae (4-6) setiform, thin, roughened. Four pairs of sacculi elongate. Notogastral lyrifissure, opisthonotal gland openings, circumgastric scissure, and circumgastric sigillar band distinct.
Gnathosoma (Figs. 2, 3). Typical for Pilobates (Ermilov and Starý 2020c; Ermilov 2020). Subcapitulum size: $188-196 \times 135-143$. Subcapitular setae ( $a$ and $m, 28-32 ; h, 41-49$ ) setiform, slightly barbed. Adoral seta (20-24) setiform, densely barbed. Palp (131-139) with typical formula. Postpalpal seta (8) spiniform, roughened. Chelicera (217-233) with two setiform, barbed setae (cha, 69-73; chb, 41-45).

Epimeral and lateral podosomal regions (Figs. 2, 3). Epimeral setal formula 3-1-3-3. All setae setiform, slightly barbed, $3 c$ (36-45) longer than $1 a, 2 a, 3 a, 4 c$ (16-20), 1b, 3b, 4a, 4b (12-16) and $1 c$ (4-6). Pedotectum II bifurcate apically in ventral view. Circumpedal carina long, directed to pedotectum II. Discidium triangular.

Anogenital region (Figs. 2, 3). Six pairs of genital $\left(g_{1}, 20-28 ; g_{2}, g_{3}, 16-20 ; g_{4}-g_{6}, 10-14\right)$, three pairs of aggenital (12-16) setae and adanal setae $a d_{3}(12-16)$ setiform, thin, slightly barbed. Two pairs of anal setae $\left(a n_{1}, 41-45 ; a n_{2}, 28-36\right)$ setiform, erect, barbed. Adanal setae $a d_{1}$ and $a d_{2}$ (90-102) thickened, erect, barbed. Adanal lyrifissure distinct. Marginal porose area complete, narrowly band-like.

Legs (Figs. 4-7). Monodactylous. Claw of all tarsi strong, barbed on dorsal side. Claw of tarsi I and II slightly thicker than claw of tarsi III and IV. Ventrobasal tubercle of tibia I blunted, ventrobasal tubercle of tibia II elongate triangular, pointed. Femur II rounded, femur III truncate or slightly concave distoventrally. Trochanter IV with long ( $1 / 2$ or $1 / 3$ length of trochanter) triangular process distodorsally. Dorsoparaxial porose area on all femora and on trochanters III, IV, and proximoventral porose area on all tarsi and distoventral porose area on all tibiae well visible. Formulas of leg setation and solenidia: I (1-5-3-4-20) [1-2-2], II (1-5-34-16) [1-1-2], III (2-3-1-3-15) [1-1-0], IV (1$2-2-3-12)[0-1-0]$; homologies of setae and solenidia indicated in Table 1. Famulus of tarsus I short, erect, slightly dilated distally, inserted between solenidion $\omega_{2}$ and seta $f t$ '. Solenidion $\omega_{1}$ on tarsus I, $\omega_{1}$ and $\omega_{2}$ on tarsus II and $\sigma$ on genu III bacilliform, other solenidia setiform. Seta $l$ " on genu I inserted on large tubercle.

Material examined. Holotype (female) and four paratypes (two males and two females): Madagascar, Andasibe-Mantadia National Park, $18^{\circ} 49^{\prime} \mathrm{S}, 48^{\circ} 26^{\prime} \mathrm{E}$, primary forest with unknown big trees, sifting litter (sample MAG-9), Winkler apparatus extraction, 26.XI.2010 (collected by R. Ravebolun and L. Rabotenoson). 


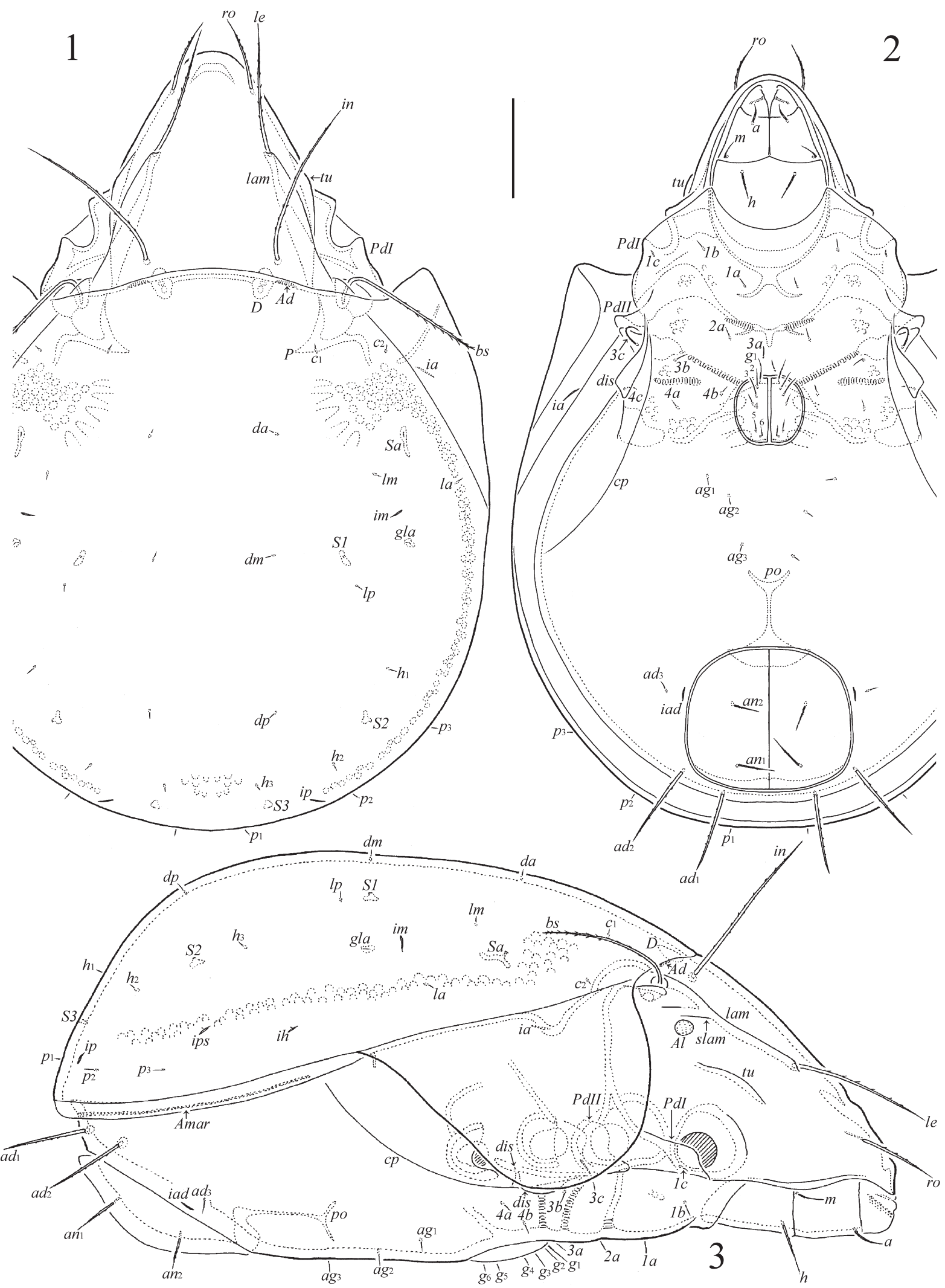

Figs. 1-3. Pilobates longiprocessus sp.n., adult: 1-dorsal view; 2-ventral view (not shown: legs); 3-lateral view (not shown: legs). Scale bar $=100 \mu \mathrm{m}$. 


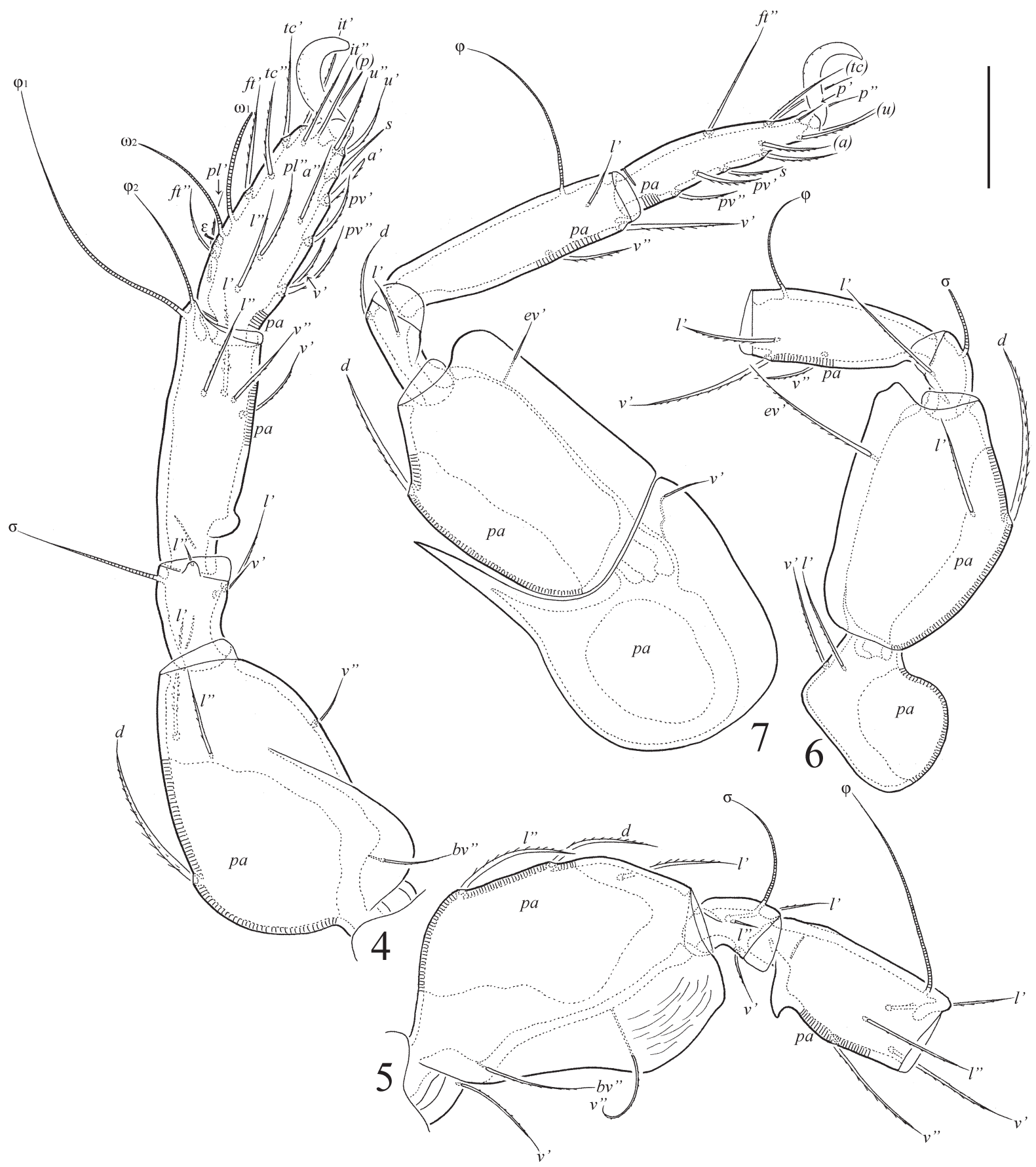

Figs. 4-7. Pilobates longiprocessus sp. n., adult: 4-leg I, right, antiaxial view; 5-leg II, without tarsus, right, antiaxial view; 6 -leg III, without tarsus, right, antiaxial view; 7-leg IV, left, antiaxial view. Scale bar $=50 \mu \mathrm{m}$.

Type deposition. The holotype is deposited in the SM; four paratypes are deposited in the TSUMZ. All in ethanol with a drop of glycerol.

Etymology. The specific name longiprocessus refers to the presence of long distodorsal process on leg trochanter IV.

Remarks. Distinctive characters of the new species, as well as of other Pilobates species, are presented in the identification key below.

\section{Key to known species of Pilobates}

1. Adanal setae $a d_{1}$ and $a d_{2}$ short (distinctly shorter than half of width of anal plate)

- Adanal setae $a d_{1}$ and $a d_{2}$ long (longer than half of width of anal plate)

2. Bothridial seta lanceolate; six pairs of genital setae; body size: $340 \times 172$

Pilobates pilosellus (Balogh, 1958) (see also Balogh 1960). Distribution: Angola, Caucasus. 
- Bothridial seta clavate; five pairs of genital setae; body size: $450-515 \times 220-280$

Pilobates carpetanus Pérez-Íñigo, 1969.

Distribution: Mediterranean.

3. Leg tridactylous; all notogastral setae of medium size (distinctly longer than diameter of bothridium) and thickened; body size: $530-647 \times 320-400 \ldots$. Pilobates incisura (Berlese, 1916) (see also Mahunka 1994). Distribution: Somalia. - Leg monodactylous; all notogastral setae short (not longer than diameter of bothridium) and setiform

4. Tutorium long, similar to lamella in length; fifteen pairs of notogastral setae (including $c_{3}$ on pteromorph)...

- Tutorium of medium size, about $1 / 2$ length of lamella; fourteen pairs of notogastral setae $\left(c_{3}\right.$ absent on pteromorph) .

5. Interlamellar seta long (longer than rostral and lamellar setae); adanal setae $a d_{1}$ and $a d_{2}$ and anal setae $a n_{1}$ with curved tip; notogaster heavily sculptured; body size: $962-979 \times 531-614$.

. Pilobates parastaryi Ermilov, 2020.

Distribution: Madagascar.

- Interlamellar seta short (distinctly shorter than rostral and lamellar setae); adanal setae $a d_{1}$ and $a d_{2}$ and anal setae $a n_{1}$ with straight tip; notogaster microsculptured; body size: 763-1,079× 547-664 ....

Pilobates staryi Ermilov, 2020.

Distribution: Madagascar.

6. All notogastral setae with attenuate tip; leg trochanter IV rounded distodorsally; body size: 614-713 × 282-381

..Pilobates africanus Ermilov and Starý, 2020(c). Distribution: Madagascar.

- All notogastral setae with straight tip; leg trochanter IV with long triangular process distodorsally; body size: 747-929 × 464-581

.Pilobates longiprocessus sp.n.

Distribution: Madagascar.

\section{ACKNOWLEDGEMENTS}

We thank R. Ravebolun and L. Rabotenoson, who collected soil and litter samples in Madagascar; and the Moravian Museum in Brno, Czech Republic, which kindly provided material for our study. We also thank Dr. Lala Harivelo Ravaomanarivo Raveloson (Department of Entomology, Faculty of Sciences, University of Antananarivo), Dr. Mamy A. Rakotoarijaona (Directeur des Opérations, Madagascar National Parks, Antananarivo) and Dr. Dimby Raharinjanahary (Chargé des
Bases de données de suivibiodiversité et recherche, Madagascar National Parks, Antananarivo) for supporting the joint Czech-Madagascan research project (2009-2014). Samples were collected in Madagascar by the Moravian Museum in Brno, Czech Republic under the collection permit No. 314/13/MEF/SG/DGF/DCB.SAP/SCB; sample exportation to the Czech Republic was done under permit No. 028N-EA02/MG14.

\section{REFERENCES}

Balogh, J. 1958. Oribatides nouvelles de l'Afrique tropicale. Revue de Zoologie et de Botanique Africaines, 58(1-2): 1-34.

Balogh, J. 1960. Descriptions complémentaires d'Oribates (Acari) d'Angola et du Congo Belge ( ${ }^{\left({ }^{\text {re }}\right.}$ série). Companhia de Diamantes de Angola, Lisboa, 51: 89-105.

Ermilov, S. G. 2020. Two new species of Pilobates (Acari, Oribatida, Haplozetidae) from Madagascar. Systematic and Applied Acarology, 25(7): 1319-1328.

Ermilov, S. G. and Starý, J. 2020a. New and interesting species of the genera Galumna and Pergalumna (Acari, Oribatida, Galumnidae) from the Montagne d'Ambre National Park, Madagascar. Acarologia, 60(1): 64-74.

Ermilov, S.G. and Starý, J. 2020b. New species and records of Oppiidae (Acari, Oribatida) from the Montagne d'Ambre National Park (Madagascar). Systematic and Applied Acarology, 25 (4): 697-706.

Ermilov, S.G. and Starý, J. 2020c. Two new species of Haplozetidae (Acari: Oribatida) from Madagascar. International Journal of Acarology, 46(3): 146-154.

Mahunka, S. 1994. Further notes, additions and redescriptions of the oribatid species preserved in the Berlese collection (Acari, Oribatida) I. Acta Zoologica Academiae Scientiarum Hungaricae, 40(1): 29-49.

Norton, R.A. 1977. A review of F. Grandjean's system of leg chaetotaxy in the Oribatei (Acari) and its application to the family Damaeidae. In: D.L. Dindal (Ed.). Biology of Oribatid Mites. SUNY College of Environmental Science and Forestry, Syracuse, pp. 33-61.

Norton, R. A. and Behan-Pelletier, V.M. 2009. Oribatida. In: G. W. Krantz and D.E. Walter (Eds.). A Manual of Acarology (TX). Texas University Press, Lubbock, Chapter 15, pp. 430-564.

Travé, J. and Vachon, M. 1975. François Grandjean. 1882-1975 (Notice biographique et bibliographique). Acarologia, 17(1): 1-19. 
Table 1

Leg setation and solenidia of Pilobates longiprocessus sp.n.

\begin{tabular}{|l|l|l|l|l|l|}
\hline Leg & $T r$ & $F e$ & $G e$ & $T i$ & $T a$ \\
\hline I & $v^{\prime}$ & $d,(l), b v^{\prime \prime}, v^{\prime \prime}$ & $(l), v^{\prime}, \sigma$ & $(l),(v), \varphi_{1}, \varphi_{2}$ & $(f t),(t c),(i t),(p),(u),(a), s,(p v), v^{\prime},(p l), l^{\prime \prime}, \varepsilon, \omega_{1}, \omega_{2}$ \\
\hline II & $v^{\prime}$ & $d,(l), b v^{\prime}, v^{\prime \prime}$ & $(l), v^{\prime}, \sigma$ & $(l),(v), \varphi$ & $(f t),(t c),(i t),(p),(u),(a), s,(p v), l^{\prime}, \omega_{1}, \omega_{2}$ \\
\hline III & $v^{\prime}, l^{\prime}$ & $d, l^{\prime}, e v^{\prime}$ & $l^{\prime}, \sigma$ & $l^{\prime},(v), \varphi$ & $(f t),(t c),(i t),(p),(u),(a), s,(p v)$ \\
\hline IV & $v^{\prime}$ & $d, e v^{\prime}$ & $d, l^{\prime}$ & $l^{\prime},(v), \varphi$ & $f t^{\prime \prime},(t c),(p),(u),(a), s,(p v)$ \\
\hline
\end{tabular}

Note: Roman letters refer to normal setae, Greek letters—to solenidia (except $\varepsilon$-famulus), Single prime (') marks setae on the anterior, and double prime (")—setae on the posterior side of a given leg segment. Parentheses refer to a pair of setae. 